\title{
Enigmatic Doctrine vs. Undetached Rabbit Parts: Language as the Object of Study for Linguists and Philosophers
}

\author{
Sofía Muñoz Valdivieso \\ Universidad de Málaga
}

\begin{abstract}
This essay surveys some of the crucial issues about language over which generative linguists and analytic philosophers have been disagreeing over the past thirty years, given that they undertake the task of analyzing language with different assumptions and goals in mind. Chomsky has been criticized by philosophers on several fronts, and the topics here discussed, such as the concept of meaning, the psychological reality of mental representations, or the view of language as innate structures as opposed to a learning process are all different aspects of the one issue at the core of their debate: the need to recur to a system of mental representations in order to explain language facts. For generative linguists language is indeed a system of mental representations; for philosophers, however, a language is a sum of actual or potential speech events, and the notion of internalized mental representations is really an unnecessary burden on any language theory.
\end{abstract}

As its somewhat cryptic title suggests, the present paper is an attempt to survey some of the major points of friction between analytic philosophers of language such as Quine and linguists within the Chomskian tradition. The title is a playful echo of W. V. Quine's statements in connection with generative grammar, a theory which he has called "enigmatic doctrine", and against which he has argued, as we shall see, using the now frequently quoted example of a rabbit as "an aggregate of rabbit parts" (Quine, "Meaning and Translation" 143). Most of the crucial issues involved in the debate between linguists and philosophers have been directly addressed by Chomsky and Quine in their own writings, their discussions focusing at points on terminological minutiae which seem to require endless clarifications and explanations. Leaving technicalities aside, the main issues are clear enough, and even a brief survey of them can tell us a great deal about the different assumptions and goals which philosophers and linguists bring into an apparently common field of study: language. 
Why and how are philosophers interested in the study of language? There have always been several areas within philosophy in which a concern with language has occurred, as in metaphysics, logic, or epistemology. More specifically, philosophy must concentrate on language whenever it deals with conceptual analysis, and this has actually been a major concern in philosophy in this century, after the rise of the British school of analytic philosophy which brought about the so-called linguistic turn in philosophy. Its basic tenet was that philosophical problems should be approached and analyzed in terms of the language used to formulate them. It thus became crucial for philosophers to proceed on the basis of some general conception of the nature of language, some understanding of the nature of linguistic use and meaning. Experts in the field recognize that the philosophy of language is "even less well-defined and less in possession of a clear principle of unity than most other branches of philosophy" (Alston 1). In general, philosophers of language have been primarily concerned with semantic concepts such as meaning, the relation between meaning and referent, or the connection between language in the mind and the external world. Although both philosophers and linguists argue that a theory of meaning must at least provide an account of the relation between linguistic structure and the external world, "opinions diverge widely on what methods it should employ and on the question whether it should incorporate or even be identified with a theory of language understanding to provide an explanation of language behaviour" (Meuten 430).

H. P. Grice's well-known proposal to define meaning in terms of use, the meaning of a linguistic expression thus reduced to a summary of its uses, is a typical example of the philosopher's attempt to obviate the need for internal representations-the issue at the core of the debate between philosophers and linguists. The origin of this use-theory of language goes back to Wittgenstein, who argued for a careful analysis of how words are used in their everyday appearance in human interaction. For him, the equation "meaning is use" was undeniable, since the meaning of a word is its use in language: “. . doesn't the fact that sentences have the same sense consist in their having the same use?" (Wittgenstein 10). In a seminal article back in the late 1950 's, Grice offered a proposal in line with Wittgenstein's conception of meaning as use. He made the primary intention of the utterer relevant to the meaning of an utterance, and he summed up what is necessary for $A$ to mean something by $\mathrm{X}$ as follows: " $\mathrm{A}$ must intend to induce by $\mathrm{X}$ a belief in the audience, and he also must intend his utterance to be recognized as so intended. But these intentions are not independent; the recognition is intended by $A$ to play its part in inducing the belief, and if it does not do so, something will have gone wrong with the fulfillment of A's intentions" (Grice 383).

According to linguists, however, Grice's definition of meaning in terms of speakers' intentions cannot hold. Paul Ziff indicates that Grice seems to have confused "A meant something by uttering X" with the quite different "A meant something by X." For Grice, "A meant something by $X$ " is equivalent to " $A$ intended the utterance of $X$ to produce some effect in an audience by means of the recognition of this intention." Ziff's argument against Grice uses the following example: George has been inducted into the army and compelled to take a test to establish his sanity. George is an irritable academic who despises the military, and he answers one of the test questions ("What would you say if you were asked to identify yourself?") with (1): 
(1) Ugh ugh blugh blugh ugh blug blug

According to Grice's definition of meaning, George did mean something by (1): he intended the utterance of (1) to produce an effect in his audience by means of the recognition of his intention. The effect he intended was that of offending his audience. But even though it is clear that George meant something by uttering (1), "it is equally clear," as Ziff indicates, "that (1) did not mean anything. Indeed, had (1) meant anything, that would have defeated George's purpose in uttering (1)" (Ziff 3). Ziff insists that to be concerned with speakers' intentions when they utter an expression is to be concerned with its use, and the use of an expression is determined by several factors, among which, some have nothing to do with meaning. At a more general level, reducing meaning to intentions does not help in the desire to do away with mental representations: we get rid of mental images but we introduce intentions.

Although Quine does not subscribe the Austinian notion of meaning-as-use, both he and Grice belong with many others in the tradition of Wittgenstein and Austin in their opposition to denotative theories of meaning, which postulate that the meaning of a word is an object, or thing, or entity. But these philosophers offer an equally virulent attack on what Quine calls the "pernicious mentalism" of generative grammar, as represented in the area of meaning by what Quine labels the Museum Myth, i.e. the notion that meaning involves something private to an individual, a mental image. Two representative examples of philosophers' arguments against mental representations in meaning are Hilary Putnam's "division of labor" and W. V. Quine's "indeterminacy of translation."

Hilary Putnam refutes any theory of meaning in which a sufficient condition for acquiring the meaning of a word is associating it with the right concept. In his view, meaning cannot be identified with intension, "if intension is anything like an individual speaker's concept" (Putnam 264). The reason? His much-discussed "division of linguistic labor": in the language of a given individual, many words are semantically indeterminate, since their extension is fixed by the community, including experts, through a complex cooperative process; extension, then, is determined socially, not by individual competence alone, and thus the psychological state of the individual speaker does not determine what he means. Semantic structure must therefore be regarded as a social rather than as a psychological fact.

For Chomsky, however, Putman's "division of linguistic labor" is not a valid argument against mental representations. If a person is unsure of the exact reference of the words "yawl" and "ketch," for instance, he will refer to experts to sharpen or fix their reference. The study of language Chomsky proposes allows for the possibility that the individual's state of knowledge may itself include some kind of reference to the social nature of language: "in the lexicon of a person's language, the entries for 'yawl' and 'ketch' will be specified to the extent of his or her knowledge, with an indication that the details are to be filled in by others" (Chomsky, Knowledge 8). That is, it is true, as Putnam suggests, that each of us will have to resort to experts to explain the meaning of words we do not fully understand, but, for Chomsky, the only conclusion we can reach from this fact is that each person has an internalized grammar which leaves certain questions open. Furthermore, as he indicates in Rules and Representations, it is highly ironic that Putnam should 
reject the Museum Myth and yet have no qualms about accepting as plausible the conclusion that the brain stores images which share share fundamental properties with pictorial representations (Chomsky, Rules 18).

In a similar vein, Quine also urges us to reject the myth that words name specimen mental objects, and his attack of the Museum Myth, a typical instance of the argument against mental representations, is articulated on the basis of his famous statement of the problem of translation, what he calls, "indeterminacy of translation," which applies not only to translations between languages but to one's own language. Quine sets a scenario for his argument:

Imagine a newly discovered tribe whose language is without known affinities. The linguist has to learn the language directly by observing what the natives say under observed circumstances, encountered or contrived... The utterances first and most accurately translated in such a case are perforce reports of observations conspicuously shared by the linguist and his informant. A rabbit scurries by, the native says 'gavagai,' and our jungle linguist notes down the sentence 'Rabbit' (or 'Lo, a rabbit') as tentative translation. (Quine, "Speaking of Objects" 5)

As Quine further develops the scenario, we have a linguist who repeats the procedure on several occasions for different rabbits in varied attitudes and under different circumstances. The linguist is therefore led to the conclusion that the word "gavagai" means "rabbit" for the native of this tribe. This is indeed the accepted scientific method. Quine, however, poses the question of behavioral evidence: we have no behavioral evidence to show whether a word such as "gavagai" stands for the concept of rabbit. For Quine the key issue is that it may be the case that this concept does not exist in this tribe's language-for all we know, they may instead think of the animal as an aggregate of independent, although attached, rabbit parts. Therefore, Quine's argument goes, since we have no definite proof that a native means "rabbit," and not "aggregate of rabbit parts," when he says "gavagai," it makes no sense to construct a theory of language that postulates the existence of a concept "rabbit"- the behavioral evidence is equally compatible with a theory in which we postulate the concept "aggregate rabbit parts."

In Chomsky's view, however, it is implausible to say of another person, whether in ours or in another culture, that he means undetached rabbit parts when he uses the term "rabbit." For him, the reason is straightforward enough. We know of ourselves that we mean rabbit and not undetached rabbit parts, and "we assume that the next person is like us in relevant ways, unless we have evidence to the contrary, just as the chemist who analyzes two samples from the same solution assumes, unless there is evidence to the contrary, that they are the same in relevant respects, or just as a geneticist assumes with regard to two fruitflies" (Chomsky, Rules 21; emphasis mine). It is true that there are ways to make all the behavioral evidence compatible with innumerable other interpretations, but this is the problem of underdetermination by evidence common to all scientific theories. In fact, what Quine's indeterminacy of translation implies is that in the area of linguistics, and cognitive science in general, the underdetermination by evidence of a theory is enough to question its validity. That is, 
psychology has been asked to confront questions that are simply dismissed in the case of the natural sciences, where no one is much concerned with the fact that two samples might in principle be differently constituted, that theories are underdetermined by evidence and so on. (Chomsky, Rules 22)

This refusal to see underdetermination in the same light across scientific endeavors is what Donald Hockey has called "the bifurcation thesis": psychology seems to face a problem of indeterminacy which is qualitatively different in some way from the underdetermination in the natural sciences. The typical objection to Chomsky's approach represented, for instance, in J. F. M. Hunter's Wittgensteinian argument in his article "On How We Talk" would never be raised against an abstract model in physics. His argument, common to most philosophers dealing with language, is that it does not follow from descriptive or predictive success that the principles postulated are the correct ones. Or, as Quine puts it, if two grammar generate the same language, it is senseless to say that one of them might be right and the other wrong.

Quine thinks of the generative linguist's concern with mental representations as an added burden which raises the problem of evidence "whereby to decide, or conjecture, which of the two extensionally equivalent systems of rules has been implicitly guiding the native's verbal behavior" (Quine, "Methodologcal Reflections" 444). As in the case of meaning, he argues that the indeterminacy of translation invalidates any theoretical move which postulates some kind of mental representation as the correct one. The insuperable problem of underdetermination affecting all aspects of language and grammar implies, according to Quine, that there is no sense to the construction of a theory of language and mind which tries to establish, for instance, that the rules of grammar assign phrase structure in one or another way in mental representations. In Quine's view, if we have two extensionally equivalent systems of grammar for a language, i.e. two systems that provide equivalent recursive definitions of well-formed string, then even if "the enigmatic doctrine under consideration says that one of the analyses is right and the other wrong," (Quine, "Methodological Reflections" 448; emphasis mine) both are equally correct. English speakers obey, in this sense, "any and all of the extensionally equivalent systems of grammar that demarcate the right totality of well-formed English sentences" (Quine, "Methodological Reflections" 444).

For Quine, language is what Chomsky would call "externalized language" ("E-language"), the actual or potential speech events. If we think of language as the sum of these speech events, grammar is then a derivative notion, a function that enumerates the elements of the E-language, and the linguist is thus free to choose one grammar or another, as long as it correctly identifies this E-language. Knowledge of language would then be a capacity or ability to do something, a system of dispositions of some kind, and behavior would provide a criterion for the possession of knowledge. Chomsky's work, on the other hand, represents precisely a deliberate shift from the study of behavior and its products to the study of states of the mind/brain that enter into behavior. A grammar is then a theory of the "internalized language" ("I-language"), i.e. a theory of the system of mental representations and computation in the mind of the persen who knows the language, and questions of truth and falsity are as pertinent for grammar as they are for any scientific 
theory. If two grammars $G$ and $G^{\prime}$ of an I-language yield the same judgement of grammaticality or form-meaning correspondence, one may certainly be chosen over the other as factually correct. Theory G' might, for instance, contain superfluous rules, or not conform to a theory of Universal Grammar which is verified for other languages, or be in conflict with some relevant evidence from the brain sciences. In short, any kind of evidence is used to select the more elegant, deeper, and more empirically adequate theory-in this case, G. In the rare case that the theories coincide on all the evidence (Quine's extensionally equivalent grammars), linguists rely on concepts of simplicity, insight and explanatory power to choose one of them. As Chomsky indicates, "this is just standard scientific practice" (Chomsky, Knowledge 250).

Philosophers, however, object to the use of this standard scientific practice when it comes to problems in the cognitive sciences, and are relunctant to adopt the "realist" assumptions of the natural sciences in the study of language. Even if the rule of movement, the principles of opacity and locality, and other representations proposed by Chomsky successfully explain facts, and even if by assuming the elements of this structure to be innate we can explain how children can reach the conclusions they reach when presented with linguistic information as they acquire language, still the theories so constructed are regarded with suspicion by philosophers if offered as theories with truth claims. It is frequently said that they lack "psychological reality"-yet another variant of the argument against imputing existence to the structure whose properties are characterized by particular grammars or universal grammars.

Sapir's discussion of the psychological reality of the phoneme is an early example of a linguistic analysis subsequently criticized for its claims to "reality." Sapir considered both linguistic and psychological evidence, and reached the conclusion that his theoretical constructions had "psychological reality"; he offered them thus as psychological real entities rather than as mere fictions convenient for some purpose. The general reaction to his claim is already familiar: his belief in the reality of the phoneme was immediately attacked. The generative linguist is often under attack for similar reasons--his way of demonstrating the reality of his constructs is not convincing enough for scholars who demand in psychology a stricter set of proofs than in the physical sciences. As Chomsky indicates, in his investigation of the language faculty the linguist observes what people say and do, and then he tries to devise a theory of some depth and significance. He tests his theory by its success in providing explanations for selected phenomena. When he is challenged to prove that these constructions have psychological reality, he can only repeat the evidence and the proposed explanations. He interprets "psychological reality" as nothing more than "truth, in a certain domain," and behaves like a scientist in the natural sciences, where he would never be asked whether the best theory he can devise in some idealized domain has the property of "physical reality."

Chomsky reminds us that in the natural sciences we seem to have no alternative but to pursue what Husserl called the "Galilean style" in physics, that is, making abstract mathematical models of the universe to which the physicists give a higher degree of reality than they accord to the ordinary world of sensation. Chomsky's endeavor moves in the same direction. He tries to discover to what extent research in the Galilean style can give us an understanding of the roots of human nature in the cognitive domain. He is therefore 
interested in pursuing the study of mind, especially "such aspects as lend themselves to inquiry through the construction of abstract explanatory theories that may involve substantial idealization and will be justified, if at all, by success in providing insights and explanations" (Chomsky, Rules 11).

On Chomsky's theory, we can propose that rule $\mathrm{R}$ is a constituent element of Jones's language (I-language) if the best model we have which deals with all the relevant evidence assigns $R$ as a constituent element of the language. And we can say that Jones follows $R$ if, in this best theory, our account of his doing such-and-such (e.g. assigning an interpretation to the sentence "Who was persuaded to like them?") makes use of $\mathrm{R}$ as a constituent of his language. These assumptions, and the basic assumption that psychological explanation is part of the natural sciences as far as rule following is concerned, are controversial for philosophers. According to Quine, Chomskian linguistics is an enigmatic doctrine, perhaps folly; in his view, we can legitimately speak of guiding only when rules are consciously applied to cause behavior-which is not what happens with language. When there is not this causal relation, we can only speak of behavior as "fitting" one or another system of rules. Bodies obey, according to Quine, the law of falling bodies, but English speakers obey any one of the grammatical systems which can account for the totality of well-formed English sentences. In Chomsky's view, Quine's comparison is irrelevant, since it merely amounts to saying that

English speakers obey any and all of the extensionally equivalent systems of grammar that demarcate the right totality of well-formed English sentences, in the sense in which bodies obey any and all of the extensionally equivalent theories that demarcate some set of arbitrarily selected proper subpart of the evidence relevant to physics. (Chomsky, Language 258)

For Chomsky, attributing causal efficacy to the rules amounts to nothing more than the claim that these rules are constituent. elements of the states postulated in an explanatory theory of behavior: we conclude that Jones is following $\mathrm{R}$ on the grounds that the best theory account for Jones's behavior includes $\mathrm{R}$ as an operative rule.

For many philosophers, in order to prove that a person is following rule $\mathrm{R}$, it must be shown that the content of the rule plays a causal role in the production of rule-governed behavior. As Searle points out, it is not enough to get rules that have the right predictive power; there must be some independent reason for supposing that the rules are functioning causally. This is why many philosophers insist that the speaker should be aware of it for something to count as a rule, and go to the extreme of saying that "we can say that someone follows a rule only if he knows what the rule is and can tell us what it is" (Cooper 145). Or, in Quine's words, "the behavior is not guided by the rule unless the behaver knows the rule and can state it" (Quine, "Methodological Reflections" 442). It is common among philosophers to claim with Searle that in order for the attribution of unconscious mental states to be legitimate, this attribution must presuppose that the states can become conscious; a condition of adequacy for any theory purporting to state the rules is, for philosophers, that the speaker must be in principle capable of being aware of how the rules enter into behavior. 
Searle indicates that speakers of English do not recognize the rules of generative grammar as being those they follow, and he claims that generative rules are too abstract and complicated, lacking the intuitive plausibility that ordinary grammar-books have. Chomsky agrees that grammar-book rules are easier to grasp, but this is the case precisely because they represent the idiosyncrasies of languages, the peculiar elements which could not be known without experience and instruction. They describe, in a way, the most intuitively outstanding phenomena that we perceive about language-which are not precisely the most interesting facts for the generative linguist studying the language faculty. No grammar-book will present rules describing, for instance, the use of reciprocals in English, because they are rules we take for granted. Good traditional grammars will say very little about general properties of language; they discuss irregularities, not deeper principles of universal grammar: these principles are automatically used by any speaker, and therefore they receive no particular attention in our daily lives.

To know a language is, for Chomsky, to have a certain mental structure consisting of a system of rules and principles which generate and relate mental representations of various types. For the most part, one cannot become aware that one knows these rules and principles, or determine by introspection that they hold. Chomsky uses the term "cognize" to refer to our knowledge of the language principles: in the case of the English sentences (2) and (3) we "cognize" their interpretations.

(2) I wonder who [the men expected to see them]

(3) The men expected to see them

In (2) the pronoun "them" may be referentially dependent on "the men," but not in the identical sentence in (3). We can say with Chomsky that the speakers cognize the facts of referential dependence because their language (I-language) provides representations (i) and (ii) for (2) and (3) respectively, and contains the principle of binding theory and those governing empty categories.

(I) I wonder [who the men expected [e to see them]]

(II) The men expected [PRO to see them]

In this case, the speakers cognize the facts and also the system of mentally represented rules from which the facts follow. We might say that "cognization" is unconscious or implicit knowledge. It is therefore correct to say (a) that the speakers know/cognize the rules at work in (2) and (3)-they understand the sentences correctly. It would be wrong to say (b) that they know that the rules hold.

Clearly, Searle and other philosophers insist that (a) and (b) should both hold for any talk of rule to make sense. If the speaker who cognizes the grammar and its rules could miraculously become aware of them, these philosophers would not hesitate to say that he knows the grammar and its rules, and that this conscious knowledge constitutes his knowledge of the language. Given that the knowledge of rules is implicit, however, philosophers cannot accept it as such. The crucial role given by linguists to unconscious structures across languages makes philosophers extremely uneasy, since they tend to think 
of language as something taught and learned, a system of habits and skills acquired gradually through generalization, conditioning, induction and abstraction, and thus they frequently express qualms concerning explanations that rely on postulated innate structures.

Philosophers naturally agree with a Piagetian vision of the child's initial state as a basic system of procedures of segmentation, classification, generalization and induction which are applied to the data of experience to yield a grammar; general principles of learning will thus underline all cognitive systems, and the various cognitive structures develop in a uniform way. For Chomsky, on the other hand, the child's genetically determined state is a rich system of principles that specify the range of possible grammars; the relation between experience and knowledge will be quite abstract. Chomsky insists that, for all we know, children learn from positive evidence only, and they appear to know the relevant facts without the appropriate experience in many complex cases. Postulating rich innate structures seems the most plausible solution to Plato's problem of "poverty of stimulus," i.e. the problem of how human beings, whose contacts with the world are brief and personal and limited, are able to know as much as they do. In the case of language, Plato's problem arises when we see that in an extremely short time, and on the basis of a limited number of heard utterances, the child becomes a master of language. It is difficult to believe that he could have obtained this mastery by only generalizing from that very small sample of language he has been offered. Such as Chomsky sees it, "it would be as if someone could become a chess-master as a result of having watched just one or two games of chess. So one is strongly tempted to suggest that the wide gap between input and output must be bridged by ascribing to the child a rich innate component" (Chomsky, Language 24). For Chomsky, children's language is a clear example of Plato's poverty of stimulus, since children at a very young age already have "a rich system of knowledge that extends far beyond any specific instruction, or experience more generally" (Davies 78). For him, the answer to Plato's problem in the field of language is very clearly that innate factors permit the organism to transcend experience, reaching a high level of complexity which does not reflect the limited environment.

Philosophers try to explain language in dispositional and other terms more closely related to actual behavior than unconscious knowledge is. Language is for them, as Quine indicates, "a social art which we all acquire on the evidence only of other people's overt behavior under publicly recognizable circumstances" (Quine, "Inscrutability" 142). Theirs is the position of the empiricist: language is essentially an adventitious construct, taught by conditioning (Quine, just like Skinner), or by drill and explicit explanation (Wittgenstein), but relatively independent in its structure of any innate mental faculties. Chomsky, on the other hand, finds that no extension of the empiricist model can give a satisfactory solution to Plato's problem, and therefore pursues the hypothesis that some aspects of the study of mind lend themselves to inquiry in the Galilean style. The language faculty is for Chomky a distinct system of the mind/brain, with an initial state $S_{0}$ (common to all species) consisting of a system of principles associated with certain parameters of variation and a markedness system. To know a language is to be in a certain state of the language faculty $S_{1}$; this state is attained by setting parameters of $S_{0}$ in one of the permissible ways on the basis of linguistic experience. 
For Chomsky, then, linguistics is the branch of psychology which deals with one specific cognitive domain, the language faculty, and linguistics as the study of I-language and $S_{0}$ will thus be incorporated within the natural siences in so far as we discover mechanisms which have the properties proposed by linguists. The main thrust of Chomsky's theory comes from his opposition to the old conception that the products of our mind (language being one) are made by men and therefore accessible to an approach quite different from that of the natural sciences. Chomsky firmly believes that the human mind must begin to be analyzed following the methods and principles of the natural sciences, and if we hope to assimilate the study of human intelligence and its products to the natural sciences insofar as possible and to learn something about nature in this way, we should devote attention to those domains in which rich and complex mental structures arise under minimal exposure to the environment. For Chomsky, language is certainly a striking example.

\section{Works Cited}

Alston, William, P. Philosophy of Language. London: Prentice-Hall, 1964.

Chomsky, Noam. Rules and Representations. New York: Praeger, 1980. . Knowledge of Language: Its Nature, Origin and Use. New York: Praeger, 1986.

. Language and Problems of Knowledge: The Managua Lectures. Cambridge: MIT P, 1988).

Cooper, David E. Philosophy and the Nature of Language. London: Longman, 1973.

Davies, Stephen. Philosophy of Language. Indianapolis: Bobbs-Merril, 1976.

Grice, H. P. "Meaning." Philosophical Review 66 (1957).

Hockney, David. "The Bifurcation of Scientific Theories and Indeterninacy of Translation."

Philosophy of Science 42 (1975): 411-27.

Hunter, J. F. M. "On How We Talk." Essays after Wittgenstein. Toronto: U of Toronto P, 1973.

Meuten, Alice ter. "Linguistics and the Philosophy of Language." Linguistics: The Cambridge

Survey. Ed. F. J. Newmeyer. Vol. 1. Cambridge: Cambridge UP, 1988.

Putnam, Hilary. "The Meaning of Meaning." Mind, Language and Reality. Ed. K. Gunderson. Cambridge: Cambridge UP, 1975.

Quine, W. V. "Speaking of Objects." Proceedings and Addresses of the American Philosophical Association, 1957-58. Yellow Springs: Antioch P, 1958.

. "Meaning and Translation." On Translation. Ed. R. A. Bower. Cambridge: Harvard UP, 1959.

"The Inscrutability of Reference." Semantics. Eds. D. Steinberg and L. Jakobovits. New York: Cambridge University Press, 1971.

- "Methodological Reflections on Current Linguistic Theory." Semantics of Natural

Languages. Ed. G. Harman and D. Davidson. New York: Humanities Press, 1972.

Wittgenstein, Ludwig. Philosophical Investigations. 3rd ed. London: Macmillam, 1968.

Ziff, Paul. “On H. P. Grice's Account of Meaning." Analysis 27 (1967). 